\title{
Two patients with COVID-19 and a fever-induced Brugada- like electrocardiographic pattern
}

\author{
S. W. E. van de Poll · C. van der Werf
}

Published online: 8 July 2020

(C) The Author(s) 2020

\begin{abstract}
Febrile states may unmask certain Brugada syndrome patients and precipitate ventricular arrhythmias. Here we describe two patients with COVID-19 who developed a fever-induced type 1 Brugada electrocardiographic pattern. Both patients did not show any ventricular arrhythmias during admission. These and previously published cases suggest that the threshold to run an ECG should be low in febrile patients with suspected COVID-19, because these patients are potentially at risk for developing proarrhythmic complications.
\end{abstract}

Keywords COVID-19 · Fever · Brugada syndrome

\section{Patient 1}

A 58-year-old man with a history of atrioventricular nodal re-entry tachycardia treated with catheter ablation, Bell's palsy and chronic facial pain presented to the emergency department with a 6-day history of fever, cough and shortness of breath. Despite being treated with amoxicillin for four days the shortness of breath had increased. The patient also complained of chest pain radiating to the back and abdominal pain on the right side. He did not report a history of syncope, and there was no relevant family history.

On examination, the patient had a fever $\left(39.0^{\circ} \mathrm{C}\right)$ and tachypnoea (respiratory rate 30 breaths per

\footnotetext{
S. W. E. van de Poll

Department of Cardiology, Franciscus Gasthuis and

Vlietland Hospital, Rotterdam, The Netherlands

C. van der Werf $(\bowtie)$

Heart Center, Department of Clinical and Experimental

Cardiology, Amsterdam Cardiovascular Sciences

Amsterdam, Amsterdam UMC, University of Amsterdam,

Amsterdam, The Netherlands

c.vanderwerf@amsterdamumc.nl
}

minute) with otherwise stable vital signs. Chest radiography showed a possible consolidation in the left lower lobe. Laboratory data demonstrated an elevated C-reactive protein level $(64 \mathrm{mg} / \mathrm{l})$. The electrocardiogram (ECG) showed sinus rhythm 88 beats per minute and a Brugada type 1-like ECG pattern in lead V1 (Fig. 1).

The patient was placed on airborne isolation precautions in a dedicated coronavirus disease-2019 (COVID-19) unit with telemetry monitoring and received antipyretic therapy (paracetamol $1000 \mathrm{mg}$ QID). He tested positive for COVID-19. He required minimal supplemental oxygen to maintain arterial saturation. There were no arrhythmias. After six days of admission, the ECG showed sinus rhythm 70 beats per minute with resolution of the Brugada-like ECG pattern (Fig. 2) and the patient was discharged.

\section{Patient 2}

A 40-year-old man without relevant past medical history presented to the emergency department with a 5day history of fever $\left(39.4^{\circ} \mathrm{C}\right)$, chills and cough. In addition, he had experienced a syncopal episode 3 days prior to his presentation. The syncope occurred in the kitchen shortly after the patient got out of bed, with-

What's new?

- A febrile state due to COVID-19 may unmask a type 1 Brugada-like electrocardiographic pattern.

- These patients are potentially at risk for developing proarrhythmic complications.

- The threshold to run an ECG should be low in febrile patients with suspected COVID-19. 


\section{Case Report}

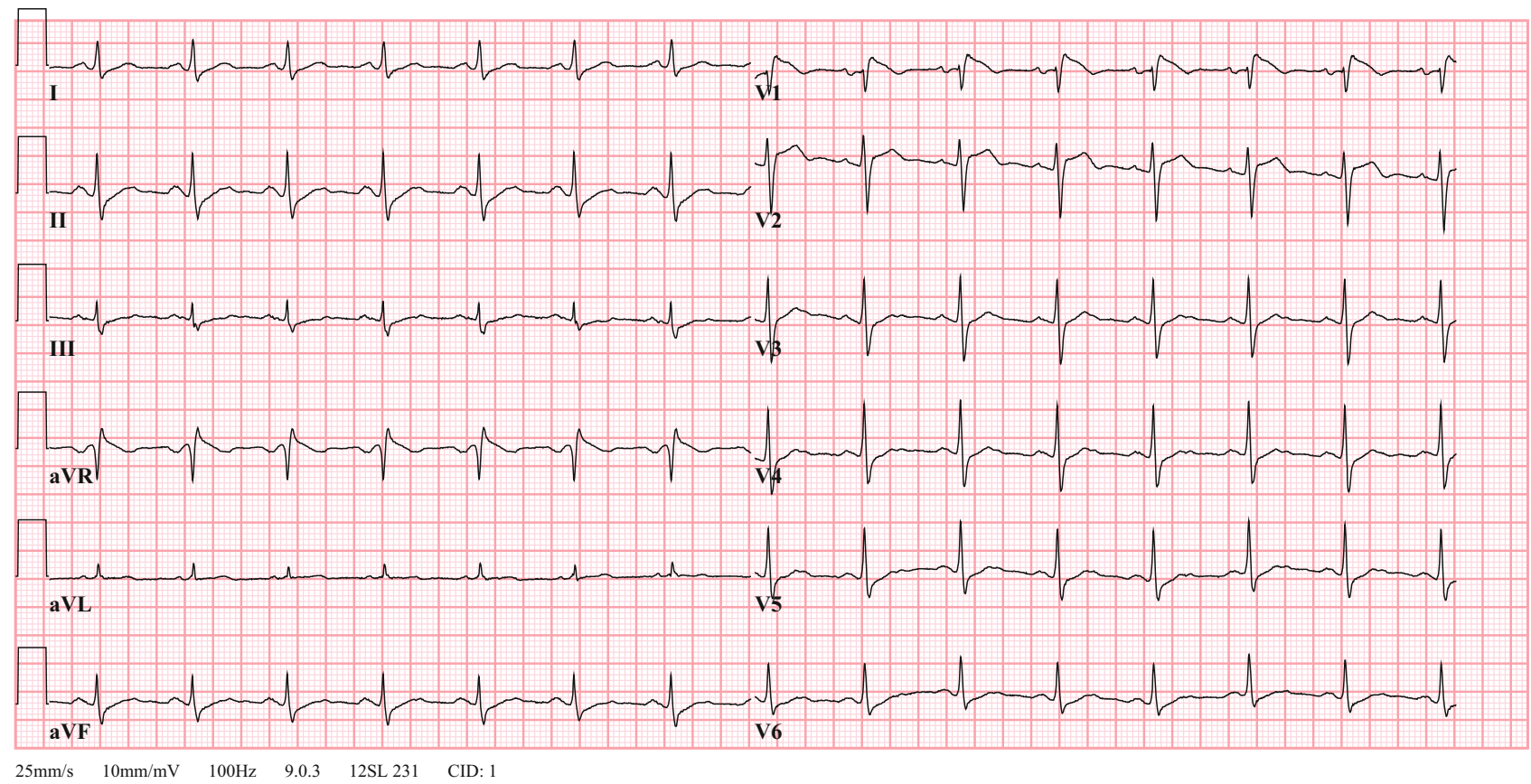

Fig. 1 Patient 1's initial 12-lead electrocardiogram in the emergency department

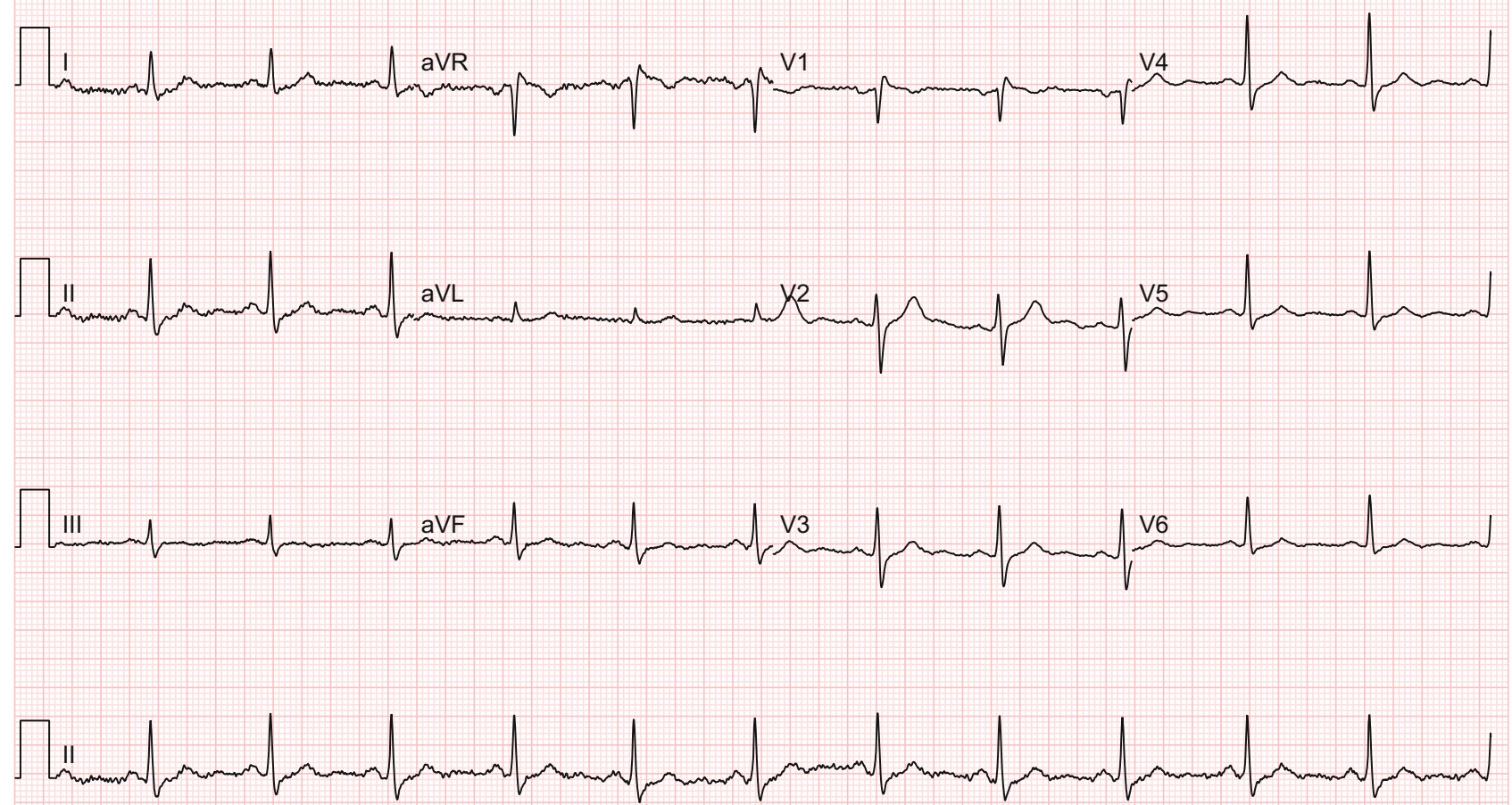

Fig. 2 Patient 1's repeat 12-lead electrocardiogram with resolution of fever

out any prodromal symptoms and with a very brief loss of consciousness. Twenty years ago, he experienced a similar event while being febrile. There was no relevant family history.

On examination, the patient was febrile $\left(38.6^{\circ} \mathrm{C}\right)$ with otherwise stable vital signs. Chest radiography showed a left-sided and possible right-sided consolidation. Laboratory data demonstrated an elevated C-reactive protein level $(100 \mathrm{mg} / \mathrm{l})$ and lactate dehydrogenase $(508 \mathrm{U} / \mathrm{l})$ and lymphopenia $\left(0.8 \times 10^{9} / 1\right)$. The electrocardiogram showed a sinus tachycardia of 


\title{
Advertisement placed here.
}

\author{
SSS bohn \\ van loghum
}

Houten 2020 


\title{
Advertisement placed here.
}

\author{
SSS bohn \\ van loghum
}

Houten 2020 


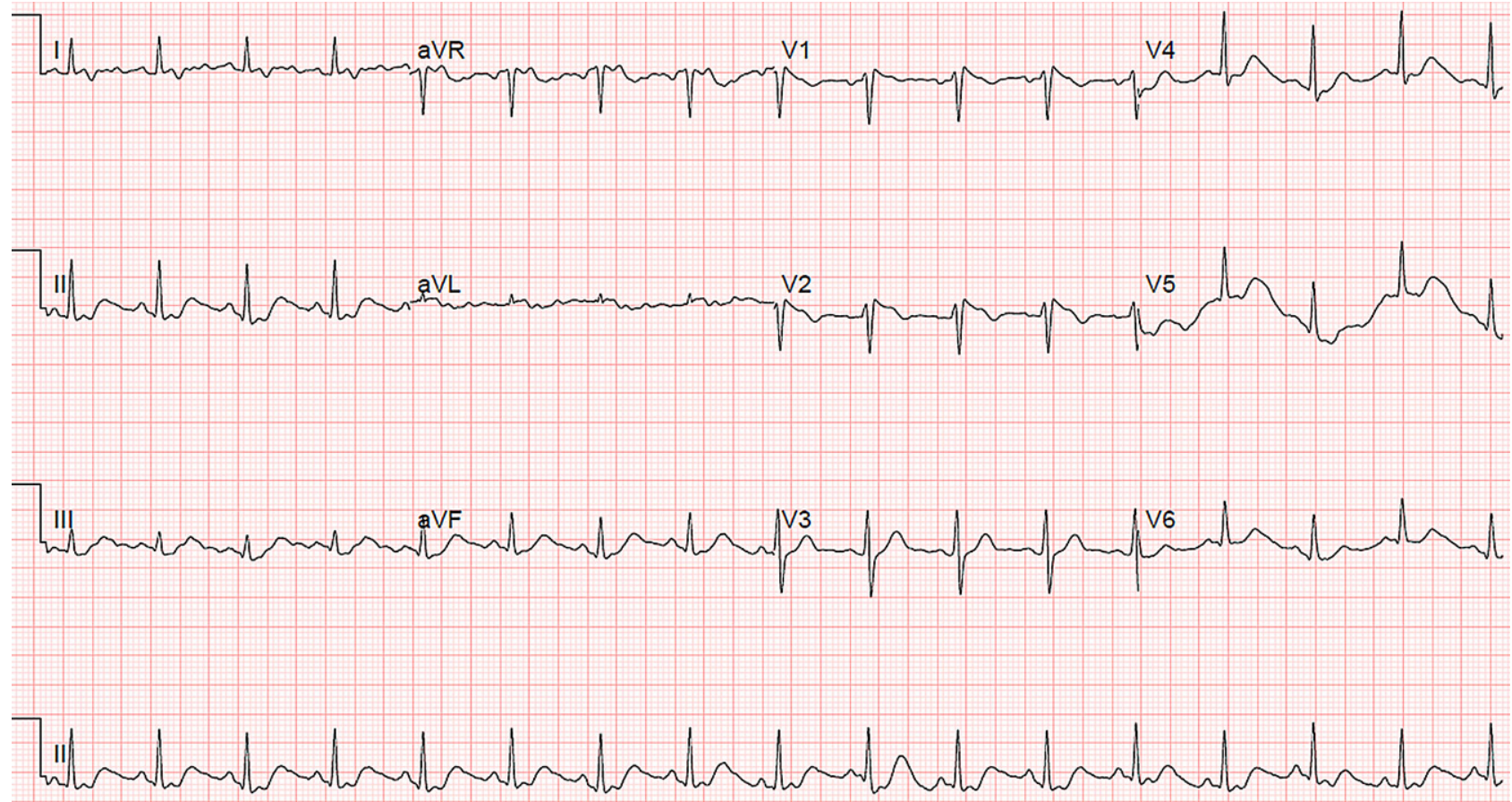

Fig. 3 Patient 2's initial 12-lead electrocardiogram in the emergency department

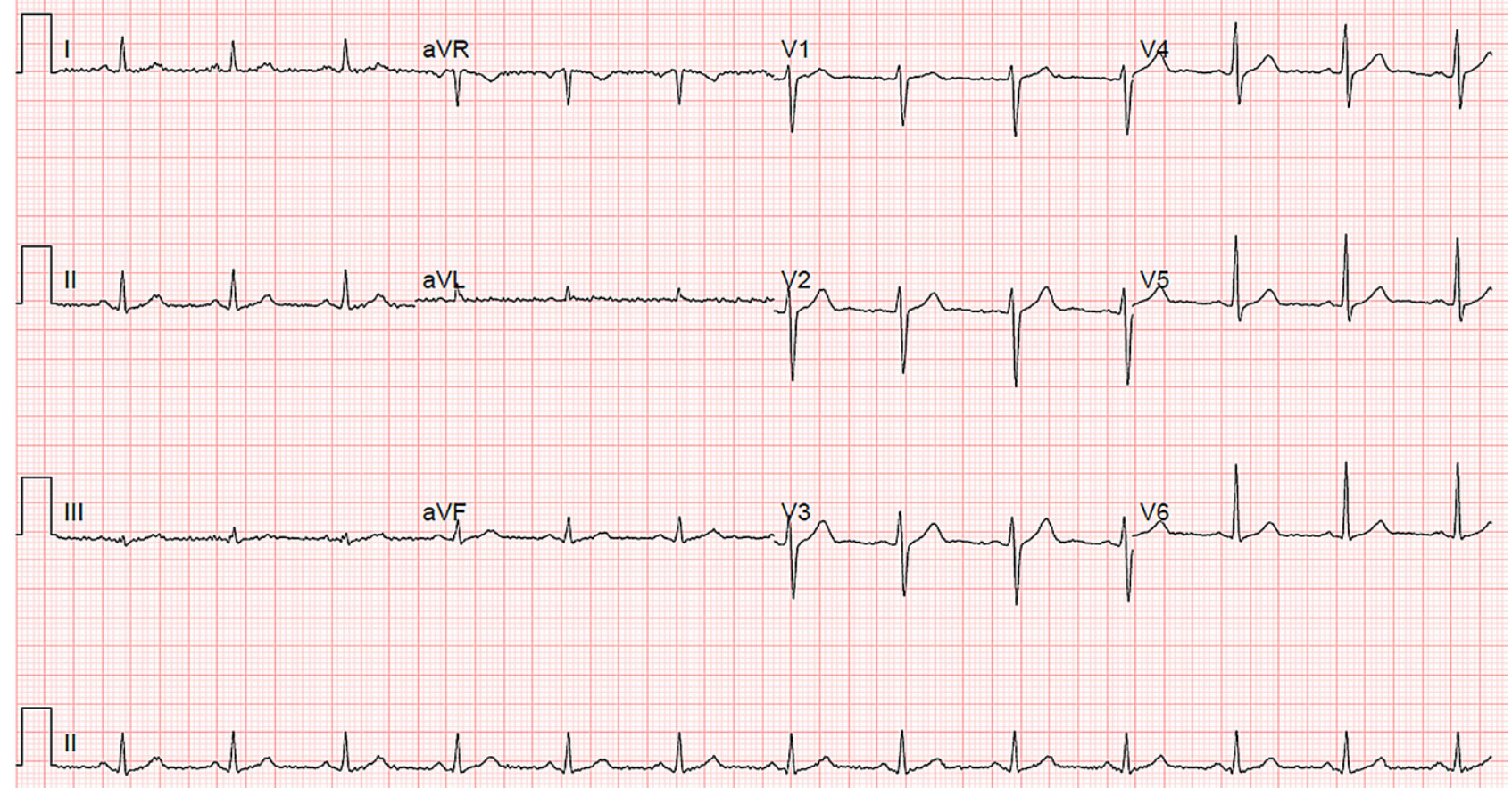

Fig. 4 Patient 2's repeat 12-lead electrocardiogram with resolution of fever

100 beats per minute and a borderline Brugada type 1-like ECG pattern in lead V1 (Fig. 3).

The patient was placed on airborne isolation precautions in a dedicated COVID-19 unit with telemetry monitoring and received antipyretic therapy (paracetamol $1000 \mathrm{mg}$ QID). He tested positive for COVID-
19. The patient's fever improved and the ECG showed a sinus rhythm of 78 beats per minute and resolution of the Brugada-like ECG pattern (Fig. 4). The patient continues to be admitted and no arrhythmias have been observed. 


\section{Discussion}

Febrile states may unmask certain Brugada syndrome patients and precipitate ventricular arrhythmias [1,2]. In a study by Adler and colleagues including 402 patients with fever, the prevalence of a Brugada type 1 ECG pattern was $2 \%$ [3]. Because fever is one of the main symptoms of COVID-19, it is conceivable that a significant number of new patients with asymptomatic Brugada syndrome will be identified during the COVID-19 pandemic. However, to our knowledge only two other patients with a COVID-19-induced Brugada-like ECG pattern have been reported $[4,5]$. The first patient presented with chest pain [4],the second patient presented with a syncopal event [5]. Both patients did not show any ventricular arrhythmias during admission.

In both patients in this report, heart rate at admission was significantly higher than during follow-up when resolution of the Brugada type 1 ECG pattern occurred. Exercise is known to aggravate the ECG phenotype in patients with Brugada syndrome [6]. Therefore, it is possible that, besides a direct effect of fever on the underlying pathophysiological substrate (e.g. loss-of-function of the voltage-gated sodium $\left[\mathrm{Na}_{\mathrm{v}}\right] 1.5$ channels), the fever-induced heart rate increase contributed to the unmasking of the Brugada type 1 ECG pattern.

A study in 112 patients with a fever-induced Brugada type 1 ECG pattern showed that $26 \%$ carried a SCN5A mutation and $80 \%$ had a positive sodium channel blocker challenge [2]. They found that the risk of ventricular fibrillation during follow-up was $0.9 \%$, which is comparable with the risk in an asymptomatic individual with a spontaneous Brugada type 1 ECG [7].

Both patients described in this case report will have follow-up, including genetic testing. However, in our opinion an implantable cardioverter defibrillator is not indicated in these patients. Patient 1 had an obvious fever-induced Brugada type 1-like ECG pattern, but was asymptomatic. In patient 2 it is possible that the syncope was non-arrhythmic and it is debatable whether the fever-induced Brugada pattern fulfils the diagnostic criteria of a type 1 pattern. In addition, fever can be effectively treated with antipyretic therapy, which probably reduces the risk of ventricular arrhythmias. Recently, Wu and colleagues described the potential COVID-19-associated risks in known patients with Brugada syndrome [8]. They recommended that febrile higher-risk patients, defined as patients without an implantable cardioverter defibril- lator who 1) have a pathogenic or likely pathogenic $S C N 5 A$ mutation, 2) are aged $<26$ or $>70$ years, or 3) have a spontaneous Brugada type 1 pattern or cardiac syncope, attend an emergency department. These recommendations now also apply to patient 2 .

In conclusion, the two previously published case reports $[4,5]$ and the two cases described in this report suggest that the threshold to run an ECG should be low in febrile patients with suspected COVID-19, because these patients are potentially at risk for developing proarrhythmic complications.

Open Access This article is licensed under a Creative Commons Attribution 4.0 International License, which permits use, sharing, adaptation, distribution and reproduction in any medium or format, as long as you give appropriate credit to the original author(s) and the source, provide a link to the Creative Commons licence, and indicate if changes were made. The images or other third party material in this article are included in the article's Creative Commons licence, unless indicated otherwise in a credit line to the material. If material is not included in the article's Creative Commons licence and your intended use is not permitted by statutory regulation or exceeds the permitted use, you will need to obtain permission directly from the copyright holder. To view a copy of this licence, visit http://creativecommons.org/licenses/by/4.0/.

\section{References}

1. Michowitz Y, Milman A, Sarquella-Brugada G, et al. Feverrelated arrhythmic events in the multicenter survey on arrhythmic events in Brugada syndrome. Heart Rhythm. 2018;15(9):1394-401.

2. Mizusawa Y, Morita H, Adler A, et al. Prognostic significance of fever-induced Brugada syndrome. Heart Rhythm. 2016;13(7):1515-20.

3. Adler A, Topaz G, Heller K, et al. Fever-induced Brugada pattern: How common is it and what does it mean? Heart Rhythm. 2013;10(9):1375-82.

4. Vidovich MI. Transient Brugada-like ECG pattern in a patient with Coronavirus Disease 2019 (COVID-19). J Am Coll Cardiol. 2020. https://doi.org/10.1016/j.jaccas.2020.04. 007.

5. Chang D, Saleh M, Garcia-Bengo Y, et al. COVID-19 Infection Unmasking Brugada Syndrome. Heart Rhythm. 2020;6:237-40. https://doi.org/10.1016/j.hrcr.2020.03. 012.

6. Amin AS, de Groot EA, Ruijter JM, et al. Exercise-induced ECG changes in Brugada syndrome. Circ Arrhythm Electrophysiol. 2009;2(5):531-9.

7. Probst V, Veltmann C, Eckardt L, et al. Long-term prognosis of patients diagnosed with Brugada syndrome: results from the FINGER Brugada Syndrome Registry. Circulation. 2010;121(5):635-43.

8. Wu CI, Postema PG, Arbelo E, et al. SARS-CoV-2, COVID-19, and inherited arrhythmia syndromes. Heart Rhythm. 2020. https://doi.org/10.1016/j.hrthm.2020.03.024. 